\title{
Detection of human antibodies to hepatitis B surface antigen (HBsAg) by an enzyme-immunoassay for HBsAg
}

\author{
G. WOLTERS, L. KUIJPERS, AND A. SCHUURS \\ From the Biochemical Research and Development Laboratories, Organon Scientific Development Group, \\ Oss, The Netherlands
}

SUMMARY We studied the feasibility of deteuting antibody to hepatitis B surface antigen (anti-HBs) by an inhibition assay using the reagents of an enzyme-immunoassay for HBsAg (Hepanostika). Several modifications of the basic assay were investigated. Sensitivity was greatest when the test sample was incubated with a predetermined amount of HBsAg before the usual procedure of HBsAg detection. The presence of anti-HBs in the test sample was shown by a reduction of the solidphase bound enzyme label.

Results were obtained with a dilution series of serum samples containing anti-HBs, the antiHBs Reference Panel of the American Bureau of Biologics, sera of hepatitis B patients, and sera of two individuals passively immunised with anti-HBs. The enzyme-immunoassay method showed at least the same sensitivity as passive haemagglutination. It was less sensitive than a commercially available radioimmunoassay (Ausab). There are no indications that non-specific reactions occur frequently.

This study also revealed that the antigenaemia of acute hepatitis-B patients can be interrupted by a transient seroconversion.

There are several techniques for the detection of antibody to hepatitis B surface antigen (anti-HBs). Techniques such as immunodiffusion and counterimmunoelectrophoresis have a relatively low sensitivity, but they are particularly useful for finding high-titre sera for specific immunoglobulin production. Passive haemagglutination (PHA) and radioimmunoassay (RIA) can detect much lower levels of anti-HBs. These methods are more appropriate for diagnostic purposes, such as in patients recovering from hepatitis $B$.

The significance of anti-HBs as an indicator of immunity against hepatitis B is not yet clear. But the use of reliable, sensitive, and easy techniques can contribute considerably to better knowledge in this matter. Both PHA and RIA have a limited accessibility for many laboratories, although they are both commercially available.

The principle of haemagglutination is simple, but, in practice, the present technique for anti-HBs detection is rather complicated. Moreover, the

Received for publication 2 July 1979 sensitised erythrocytes have a very short shelf-life. RIA can be performed only by well-equipped and licensed laboratories. The radioactive label has a limited shelf-life.

In this report we describe an enzyme-immunoassay (EIA) for the detection of anti-HBs using Hepanostika reagents, based on inhibition. This method can be particularly useful if Hepanostika is used as a screening test for hepatitis B surface antigen (HBsAg) and if a longer shelf-life is desired.

\section{Material and methods}

NORMAL HUMAN SERUM

Normal human serum was selected on the basis of the absence of $\mathrm{HBsAg}$ in enzyme-immunoassay and anti-HBs in radioimmunoassay. It was stored at $-20^{\circ} \mathrm{C}$.

STANDARD HBSAg

Human sera of subtype ad or ay were diluted 1:24 in $0.1 \mathrm{~mol} / 1 \mathrm{Na}_{2} \mathrm{HCO}_{3}$ solution, heated for 10 hours at $60^{\circ} \mathrm{C}$, and subsequently dialysed against $9 \mathrm{~g} / \mathrm{l}$ 
$\mathrm{NaCl}$ solution. The HBsAg content in these stock solutions was determined in nanograms HBsAg per millilitre by EIA on the basis of the 1st Panel of the National Reference Centre for virus hepatitis at the Institute of Hygiene of the University of Göttingen, West Germany. The HBsAg subtype was determined by immunodiffusion in agarose.

A stock solution of each subtype was stored at $-20^{\circ} \mathrm{C}$ and thawed only once. Dilutions were made in $0.11 / 1(1: 10)$ normal human serum, containing $9 \mathrm{~g} / \mathrm{l} \mathrm{NaCl}, 0 \cdot 1 \mathrm{~mol} / 1 \mathrm{glycine}$, and $1 \mathrm{~g} / \mathrm{l}$ sodium azide. They were stored at $2-8^{\circ} \mathrm{C}$.

\section{HUMAN ANTI-HBS}

Human sera that were positive by immunodiffusion were used for the dilution series. The subspecificity was determined by immunodiffusion and by EIA, as previously described (Wolters et al., 1976).

\section{ORIGIN OF TEST SAMPLES}

The Bureau of Biologics (BOB) anti-HBs panel no. 1 was kindly provided by the United States Department of Health, Education, and Welfare, Public Health Service, Bureau of Biologics, Food and Drug Administration.

Serial serum samples from hospitalised patients with acute viral hepatitis B were obtained by courtesy of Professor V. Mudric, School of Medicine, University of Novi Sad, Yugoslavia.

Sera from healthy blood donors were obtained from the Medical Haematological Laboratory Blood Bank, Munich, West Germany.

Sera were collected from two healthy subjects who had been passively immunised with human antiHBs according to the prescriptions of the Central Laboratory of the Blood Transfusion Service of the Netherlands Red Cross.

PASSIVE HAEMAGGLUTINATION FOR ANTIHBS

Anti-HBs was detected with HBsAg-coated red cells (Virgo Reagents, Electronucleonics Laboratories, Bethesda, Maryland, USA) according to the manufacturer's instructions.

RADIOIMMUNOASSAY FOR ANTI-HBS

The RIA for anti-HBs was the Ausab test (Abbott Laboratories, North Chicago, Illinois, USA).

ENZYME-IMMUNOASSAY FOR HBSAG HBsAg was detected by the Hepanostika ${ }^{R}$ Microelisa system (Organon Teknika, Holland) according to the instructions of the manufacturer.

ENZYME-IMMUNOASSAY FOR ANTI-HBS

The method for detection of anti-HBs was based essentially on the principle that a positive reaction of $\mathrm{HBsAg}$ in Hepanostika was inhibited by the presence of anti-HBs.

Four procedures (A, B, CI, and CII) using Hepanostika reagents were investigated (Table 1 ). The concentration of standard $\mathrm{HBsAg}$ necessary for each procedure had been determined previously. For a high sensitivity, the concentration should not be too high. On the other hand, the concentration should not be too low for good readability and reproducibility of the test result. In all four systems we aimed at the same reaction, also between different test runs, of the standard $\mathrm{HBsAg}$ in case anti-HBs was absent in the test sample. This reaction, expressed as absorbance at a wavelength of $492 \mathrm{~nm}$ (A492), was allowed to range from 0.3 to 0.9 . These values correspond with an amount of standard $\mathrm{HBsAg}$ of 0.5 to $1.2 \mathrm{ng}$ per well, depending on the procedure under investigation and on the subtype of the standard HBsAg. Controls and the reading and calculation of final results were essentially the same in all procedures.

The test performance of procedure $\mathbf{A}$ is described below:

1 Add $0.1 \mathrm{ml}$ of test sample to each of two test tubes ( $\mathrm{X}$ and $\mathrm{Y}$ ).

2 Add $0.025 \mathrm{ml}$ of standard HBsAg $(25-60 \mathrm{ng} / \mathrm{ml})$ to tube $X$.

3 Add $0.025 \mathrm{ml}$ of $9 \mathrm{~g} / 1 \mathrm{NaCl}$ solution to tube $\mathrm{Y}$.

4 Cover the tubes and mix well.

5 Incubate for $20( \pm 4)$ hours at $37^{\circ} \mathrm{C}$.

6 Add $0.1 \mathrm{ml}$ of the contents from tubes $X$ and $Y$ to adjacent wells of a Hepanostika Microelisa plate.

7 Continue with the normal procedure of the Hepanostika screening test.

A negative control (ie, free from $\mathrm{HBsAg}$ and antiHBs) was tested according to this set-up in each plate five times and an anti-HBs positive control twice.

Interpretation of the results read with the naked eye in wells $\mathrm{X}$ and $\mathrm{Y}$ was as follows:

$\mathrm{X}=$ colour as strong as Negative for anti-HBs negative control (eg, found for negative control)

\begin{tabular}{|c|c|}
\hline $\begin{aligned}= & \text { no colour or slightly } \\
& \text { more than } Y, \text { but } \\
& \text { definitely less inten- } \\
& \text { sive than negative } \\
& \text { control } \\
Y= & \text { no colour }\end{aligned}$ & $\begin{array}{l}\text { Positive for anti-HBs } \\
\text { (eg, found for positive } \\
\text { control) }\end{array}$ \\
\hline$X=$ colour & $\begin{array}{l}\text { Possibly positive for } \\
\text { HBsAg }\end{array}$ \\
\hline $\begin{aligned} & Y= \text { colour stronger than } \\
& \text { negative control }\end{aligned}$ & $\begin{array}{l}\text { No demonstrable } \\
\text { anti-HBs }\end{array}$ \\
\hline
\end{tabular}


Table 1 Procedures of anti-HBs test using Hepanostika reagents



$\mathrm{Ag}=$ standard HBsAg

$\begin{aligned} & A g \\ & S P\end{aligned}-\mathbf{A b}=$ solid phase anti-HBs (Hepanostika-Microelisa plate) symbolised by $V$

$A b-E=$ enzyme-labelled anti-HBs (Hepanostika conjugate)

-Incubation of $2 \mathrm{~h} / 37^{\circ} \mathrm{C}+20 \mathrm{~h} / 4^{\circ} \mathrm{C}$ was also tested.

Results measured photometrically were interpreted by calculating the percentage of inhibition:

$$
100-\frac{A(X \text { sample })-A(Y \text { sample })}{A(X \text { neg })-A(Y \text { neg })} \cdot 100,
$$

where A (X sample) and A (Y sample) represent $\mathbf{A}_{492}$ for the samples in wells $X$ and $Y$ respectively, and $A(X$ neg) and $A(Y$ neg) the corresponding reactions for the negative control $(=$ anti-HBs negative).

Inhibition of $50 \%$ or more was regarded as positive for anti-HBs.

\section{Results}

\section{COMPARISON OF DIFFERENT PROCEDURES}

Dilutions of a human serum containing antibodies to the HBsAg subtype ay, as well as dilutions containing anti- $a d$, were tested with procedures $\mathrm{A}, \mathrm{B}$, and CI. A typical result is shown in Figure 1. This graph demonstrates that at $20^{\circ} \mathrm{C}$ procedure $A$ gives the curve with the highest response, whereas procedure $\mathrm{CI}$ is the least sensitive.

When in procedures $\mathbf{A}, \mathbf{B}$, and $\mathbf{C I}$ incubation with the sample was for 20 hours at $37^{\circ} \mathrm{C}$ and all other

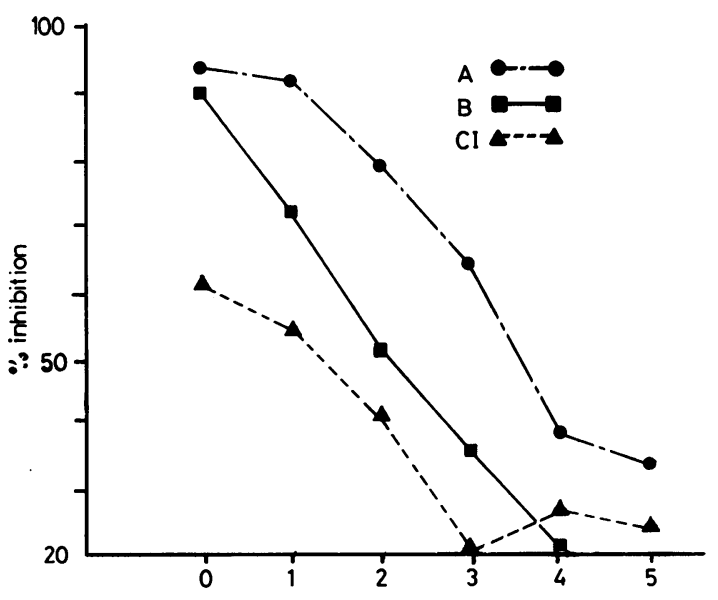

Dilution of anti-HBs $\left(1: 250 \times 2^{\times}\right)$

Fig. 1 Comparison of three procedures $(A, B$, and $C I)$ for the detection of human anti-HBs with an overnight preincubation (in $\mathrm{A}$ and $\mathrm{CI}$ ) at $20^{\circ} \mathrm{C}$. All other incubations were for 2 hours at $37^{\circ} \mathrm{C}$. The anti-HBs serum contained antibodies against HBsAg determinants $\mathrm{a}$ and $\mathrm{y}$. The standard HBsAg used for the test had subtype ay. The percentage of inhibition of the reaction of standard HBsAg is a measure of anti-HBs activity. 
incubations were for 2 hours at $37^{\circ} \mathrm{C}$ (see Table 1), procedure $\mathbf{A}$ again was more sensitive, although less pronounced, that is, by only $10 \%$ more inhibition. Incubation of the sample for 2 hours at $37^{\circ} \mathrm{C}$ followed by 20 hours at $4^{\circ} \mathrm{C}$ was less sensitive than overnight incubation at $37^{\circ} \mathrm{C}$ as above.

Figure 2 shows that in procedure $\mathrm{A}$ overnight incubation of samples with antigen is better at $37^{\circ} \mathrm{C}$ than at $20^{\circ} \mathrm{C}$.



Fig. 2 Effect of temperature on first incubation (overnight) tested with procedure $A$ for the detection of anti-HBs (human). The anti-HBs serum contained antibodies against $\mathrm{HBs} \mathrm{Ag}$ determinants a and $\mathrm{y}$. The standard HBsAg used for the test had subtype ay. The percentage of inhibition of the reaction of standard HBsAg is a measure of anti-HBs activity. $37^{\circ} \mathrm{C} ; \Delta--\Delta 20^{\circ} \mathrm{C}$.

Although procedures $\mathrm{B}$ and $\mathrm{CI}$ are less sensitive than procedure $A$, they are attractive test systems as they are performed directly in the plate. Procedure CI was further simplified, thus resulting in procedure $\mathrm{CII}$ : in this modification, the first two incubation steps were for 1 hour at $37^{\circ} \mathrm{C}$ each, and the first wash step was omitted. Figure 3 presents typical results of a comparison between procedure CII and A (at $37^{\circ} \mathrm{C}$ ) when a dilution series of antiHBs was tested. It shows how different sensitivities can be found with different test procedures.

Procedure A, as described under Material and methods (that is, with overnight incubation at $37^{\circ} \mathrm{C}$ ), was finally chosen for further evaluation and comparative studies.

COMPARISON OF EIA WITH OTHER TECHNIQUES FOR ANTI-HBS DETECTION Procedure A was subsequently compared with RIA and PHA.

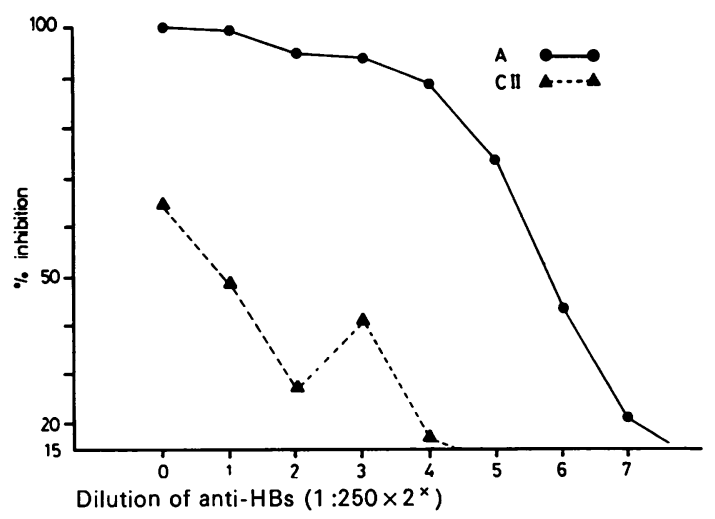

Fig. 3 Comparison of procedures $A$ and $C I I$ for the detection of anti-HBs (human). All incubations were at $37^{\circ} \mathrm{C}$. The anti-HBs serum contained antibodies against HBs Ag determinants a and y. The standard HBs Ag used for the test had subtype ay. The percentage of inhibition of the reaction of standard $\mathrm{HBs} A \mathrm{~g}$ is a measure of anti-HBs activity.

Dilutions series

Endpoint dilutions of human anti-HBs were determined for EIA inhibition, RIA, and PHA. The results are given in Table 2 .

Table 2 Titration of human anti-HBs of two different subspecificities

\begin{tabular}{|c|c|c|}
\hline & Anti ad & Anti ay \\
\hline $\begin{array}{l}\text { PHA } \\
\text { EIA } \\
\text { RIA }\end{array}$ & $\begin{array}{r}1000 \\
2000 \\
4000 \\
2000 \\
64000\end{array}$ & $\begin{array}{r}2000 \\
16000 \\
8000 \\
8000 \\
1024000\end{array}$ \\
\hline
\end{tabular}

Endpoint dilutions for PHA and EIA corresponded with an RIA ratio of $30-60$.

\section{$B O B$ panel}

The results with the BOB Reference Panel No. 1 for anti-HBs (Table 3) showed that EIA detected all antibody-positive samples 'required for release' when the corresponding subtype was used as the standard antigen. One anti-ay-positive sample (No. 101) was missed by EIA using subtype $a d$. The seven anti-HBs negative sera were not reactive with EIA.

\section{Anti-HBs negative sera}

Sera from 30 healthy blood donors who were negative for anti-HBs by RIA were all negative by EIA except one. This serum showed $60 \%$ inhibition with subtype $a d$. 
Table 3 Results of anti-HBs detection by EIA in samples of the BOB Reference Panel No. 1

\begin{tabular}{|c|c|c|c|}
\hline \multirow[t]{3}{*}{ Category } & \multirow[t]{3}{*}{ Number } & \multicolumn{2}{|c|}{$E I A+$} \\
\hline & & \multicolumn{2}{|c|}{ Subtype of standard antigen } \\
\hline & & ad & ay \\
\hline \multirow{3}{*}{$\begin{array}{l}\text { Anti-HBs positive } \\
\text { 'required for release' } \\
\text { anti-ay } \\
\text { anti-ad }\end{array}$} & 10 & & \\
\hline & 6 & $5+$ & 6 \\
\hline & 4 & 4 & 4 \\
\hline \multirow{3}{*}{$\begin{array}{l}\text { Anti-HBs positive } \\
\text { 'not required for relsase' } \\
\text { anti-ay } \\
\text { (Nos. 111, 113, 115) } \\
\text { unspecified } \\
\text { (No. 119) }\end{array}$} & 4 & & \\
\hline & 3 & $1^{*}$ & $1^{*}$ \\
\hline & 1 & 0 & 0 \\
\hline Anti-HBs negative & 7 & 0 & 0 \\
\hline
\end{tabular}

*No. 111

+No. 101 was missed

$\mathrm{HBs} A \mathrm{~g}$ and anti-HBs in acute hepatitis $\mathrm{B}$ patients

In the first instance we studied 19 patients who had been followed previously for the presence of $\mathrm{HBsAg}$ (Wolters et al., 1977). During their stay in hospital seroconversion was demonstrated by RIA and EIA, as shown in Figure 4. Four patients had detectable anti-HBs (as found by RIA) during antigenaemia. However, in two of these patients RIA for HBsAg had already become negative, whereas EIA was still positive for HBsAg. In total, we tested 21 patients, including the 19 mentioned above. The results are summarised in Table 4. AntiHBs was detected sooner or later in 15 patients by RIA, and was confirmed in 11 by EIA. There were no samples positive by EIA only. Anti-HBs was detected earlier by RIA than by EIA in at least nine patients. All anti-HBs positives that were negative by EIA had $P / N$ ratios of less than 14 by RIA. Antigenaemia of subtype ad had been involved in one, and of subtype $a y$ in three, of the four patients with anti-HBs that was detected by RIA only. Six of the 11 patients who were antibody-positive by both EIA and RIA had shown a subtype ay antigenaemia, whereas five were untypable.

The patterns of antigenaemia and seroconversion in the 21 patients studied could be divided into two main types. This is shown in Figure 5.

Fourteen patients of type $I$ showed a reduction followed by a disappearance of $\mathrm{HBsAg}$ during reconvalescence. They all remained negative for HBsAg. Seroconversion was demonstrated by both EIA and RIA in at least $50 \%$. In the seven type II patients, reduction and disappearance of $\mathrm{HBsAg}$ was followed by a recurrence of the antigenaemia. During the HBsAg-negative period of four patients, anti-HBs was found by both EIA and RIA. Three



Fig. 4 Anti-HBs in sera from 19 acute hepatitis $B$ patients after their first antigenaemia (some patients had a recurrence of $\mathrm{HBs} \mathrm{Ag}$, as was found in our previous study).

patients were also followed by PHA. Figure 6 shows the results of both PHA and EIA for antiHBs in the reconvalescent period in which seroconversion could be demonstrated by RIA. EIA became positive earlier than PHA in these patients.

Table 4 Anti-HBs in 21 patients recovering from acute hepatitis $B$

\begin{tabular}{|c|c|c|c|c|c|c|}
\hline & \multirow{3}{*}{$\begin{array}{l}\begin{array}{l}\text { No } \\
\text { anti-HBs }\end{array} \\
R I A / E I A\end{array}$} & \multicolumn{5}{|c|}{ Anti-HBs } \\
\hline & & \multirow[t]{2}{*}{$R I A$} & \multicolumn{2}{|c|}{$E I A$} & \multirow[t]{2}{*}{$R I A>E I A \dagger$} & \multirow[t]{2}{*}{$R I A=E I A \dagger$} \\
\hline & & & ay & ad\| & & \\
\hline $\begin{array}{l}\text { Total } \\
\text { Subtype }\end{array}$ & 6 & 15 & 11 & 8 & $9(10)$ & $6(5)$ \\
\hline$a y$ & $4^{*}$ & 9 & 6 & 4 & $4 \ddagger$ & 5 \\
\hline ad & 1 & 1 & 0 & 0 & 1 & 0 \\
\hline$?$ & 1 & 5 & 5 & 4 & $4(5) \S$ & $1(0)$ \\
\hline
\end{tabular}

*One patient was positive for HBsAg throughout the study.

+Anti-HBs detected earlier by RIA than by EIA (RIA $>$ EIA) or simultaneously by RIA and EIA (RIA = EIA); the results are given for the standard antigen used in EIA of the corresponding subtypes or the results with both subtypes, if the subtype was unknown (ad in brackets).

¥Two patients were still positive for $\mathrm{HBsAg}$ by EIA only, and one patient was positive for HBsAg by both EIA and RIA at the time ant1-HBs was demonstrable by RIA.

§One patient was still positive for HBsAg by both EIA and RIA at the time anti-HBs was demonstrable by RIA.

\|All positives with ad antigen were also demonstrable with ay antigen.

\section{Detection of passive immunity}

Two healthy subjects who had received a prophylactic dose of specific human anti-HBs immuno- 




Patient 10



Fig. 5 Two types of HBs Ag/anti-HBs patterns in 21 acute hepatitis $B$ patients. Type I: disappearance of HBs Ag, followed by either detection of anti-HBs or negative for both $\mathrm{HBs} \mathrm{Ag}$ and anti-HBs.

Type II: temporary disappearance of $\mathrm{HBs} \mathrm{Ag}$, during which period either negative or positive for anti-HBs.

Fig. 6 Seroconversion of three patients recovering from acute hepatitis $B$. (The subtype of $\mathrm{HBs} \mathrm{Ag}$ in these patients could not be determined.) The upper part shows the results obtained with PHA for anti-HBs using ad-coated cells $(\bigcirc)$ and aycoated cells $(\bigcirc)$. The lower part shows the results obtained with EIA inhibition for anti-HBs using standard HBs Ag of subtype ad (O) and subtype ay (○). The time on the abscissa starts in the week in which the RIA for anti-HBs was positive for the first time. The broken lines indicate the cut-off between positive (above) and negative (below) results. 
globulin were followed for up to 35 days. Neither subject had had anti-HBs, as judged by PHA, EIA, or RIA, before injection. Anti-HBs was no longer detected by PHA after six days in one individual or after 12 days in the other. EIA was still positive with standard antigen of both subtypes. Both subjects were still positive by RIA and EIA after 35 days, though by EIA only with standard antigen of subtype ad.

\section{Discussion}

In addition to screening for $\mathrm{HBsAg}$, testing for anti-HBs is valuable in epidemiological studies and in monitoring patients and high-risk groups such as medical and laboratory staff in hospitals and renal dialysis units. Detection of anti-HBs is also useful for following the presence of passive immunity against hepatitis $\mathrm{B}$ in persons who have received specific immune globulin as prophylaxis. In the future, when active immunisation can be expected, tests for anti-HBs will give the first indication that immunisation has been effective.

Whereas the presence of HBsAg in blood is assumed to be an indication of replication of hepatitis $B$ virus, the presence of anti-HBs is considered a marker for immunity against hepatitis B. It is not known to what extent very low levels of anti-HBs are protective. Nevertheless, the relatively insensitive immunodiffusion and counterimmunoelectrophoresis methods do not seem to be suitable for this purpose.

PHA and RIA, which are both commerically available, are certainly sufficiently sensitive. However, they have the disadvantage that at least some of the reagents are relatively unstable. Moreover, RIA has the usual disadvantages of working with radioactive isotopes, such as the disposal of radioactive waste, specially trained personnel, expensive laboratory facilities and equipment, and, in many countries, a special licence from the authorities.

An enzyme-immunoassay, as developed for the detection of HBsAg (Wolters et al., 1976), has been shown to be a good alternative to RIA. The same reagents can be used for the detection of anti-HBs on the basis of inhibition of the $\mathrm{HBsAg}$ reaction by anti-HBs in the test sample.

We have tried to find the most sensitive modification with minimal adaptations of the original EIA for HBsAg. Our results showed that preincubation of HBsAg with the test sample (procedure A) gives a higher sensitivity than a modification in which the HBsAg is already bound to the solid phase (procedures CI and CII) or a modification in which the anti-HBs is in competition with solidphase antibody (procedure B).
Lange and Köhler (1978) found the same sensitivity with procedures $\mathrm{CI}$ as with procedure $\mathrm{A}$, which contrasts with our results. For reasons of sensitivity, procedure $A$ with a preincubation of 2 hours at $37^{\circ} \mathrm{C}$ was the method of our choice. The results were available after 24 hours. Procedure A was not the most practical one. It was important that the sample was preincubated in small, preferably conical tubes. Evaporation should be limited as far as possible.

For all procedures the accurate addition of standard HBsAg was necessary to obtain reliable results. This was, of course, more critical for procedures $\mathrm{A}$ and $\mathrm{B}$, where the relatively small volume of $0.025 \mathrm{ml}$ was to be added.

If one needs a simple and short test, procedure $B$, using two incubations of 2 hours at $37^{\circ} \mathrm{C}$, is preferable. This method is performed directly in the test plate and runs parallel with the screening procedure of the test for HBsAg. Its sensitivity, however, was approximately three times less than that of procedure $A$.

The relative sensitivity of procedure A was studied with different types of samples. A dilution series of two human sera containing anti-HBs showed a similar sensitivity for EIA and PHA. The RIA had a much higher titre (Table 2).

The EIA meets the requirements for release by the American Bureau of Biologics. Only one serum (No. 101) having antibody specificity for the ay subtype was missed by EIA if tested with standard antigen of the ad subtype. Another serum (No. 111), that is positive by RIA but generally missed by PHA, was detected by EIA.

Thirty sera found to be negative by RIA were also unreactive by EIA, indicating that falsepositive reactions are rare.

A follow-up study of hepatitis B patients demonstrated that RIA detected anti-HBs after disappearance of $\mathrm{HBs} A g$ in a number of patients earlier than EIA (Fig. 4; Table 4). It is remarkable that, in two cases, RIA was positive for anti-HBs and negative for $\mathrm{HBsAg}$, whereas EIA was positive for HBsAg. This discrepancy may have been caused by immune complexes to which RIA and EIA react differently.

This follow-up study of 21 patients showed that in 14 patients $\mathrm{HBsAg}$ disappeared (type I in Fig. 5). In at least $50 \%(7 / 14)$ seroconversion was demonstrated within the period of testing. Most interesting was the phenomenon in the other seven (type II) of the 21 patients, viz, that after disappearance of HBsAg the antigenaemia returned. The presence of anti-HBs during the intermittent period was found in at least three of these patients. Apparently a negative $\mathrm{HBs} \mathrm{Ag}$ and even a positive anti-HBs may not always mean a complete recovery from hepatitis 
B. It would, of course, be interesting to study other markers of hepatitis B virus in such sera, such as anti-HBc, anti-HBe, and $\mathrm{HBeAg}$. This will be the subject of future investigations.

EIA was more sensitive than PHA in this followup study (Fig. 6). A similar conclusion can be drawn from the results in healthy individuals who had received an injection of anti-HBs-containing immunoglobulin.

This study has demonstrated that EIA for the detection of HBsAg can also be used as a test for anti-HBs. The direct sandwich RIA for anti-HBs using labelled HBsAg appeared to be more sensitive than an indirect EIA based on the inhibition of a sandwich assay for HBsAg.

The difference in sensitivity between the direct RIA and the EIA inhibition method was more pronounced in the dilution series than in the followup study of hepatitis B patients. We have no explanation for the phenomenon that anti-HBs dilutions giving $\mathrm{P} / \mathrm{N}$ ratios of up to 60 by RIA were negative by EIA, whereas undiluted sera of patients giving similar $\mathbf{P} / \mathbf{N}$ ratios were reactive by EIA. The latter comparison is, of course, more realistic. A direct sandwich test may be more sensitive, by definition, as the formation of a 'bridge' between solid-phase antigen and labelled antigen needs only one antibody, whereas for the neutralisation of a large antigen with many reactive sites many antibodies are necessary. A solid-phase RIA inhibition test for antiHBs has been described by others (Leonard et al., 1974; Müller et al., 1975; Pesendorfer, 1976; Forghani et al., 1977). Forghani et al. (1977) detected slightly more anti-HBs sera with their method than by PHA.

Pesendorfer (1976) found that his RIA inhibition method, which did not differ essentially from our test procedure with enzyme-labelled antibody, was only slightly less sensitive than the direct sandwich RIA (Ausab): the difference was a factor of about 3 on the basis of $50 \%$ inhibition. This does not seem to support the above-mentioned hypothesis.

Although we may speculate that a direct sandwich EIA for anti-HBs will also be more sensitive than an EIA inhibition test, we conclude from our results that the latter method meets the current requirements for sensitivity. It can at least compete with PHA, which is widely accepted as a sensitive test. The EIA has the advantage that the reagents are stable for longer periods. An additional advantage is that screening for both $\mathrm{HBs} \mathrm{Ag}$ and anti-HBs can be done with the same reagents at the same time.

\section{References}

Forghani, B., Schmidt, N. J., and Lennette, E. H. (1977). Radioimmunoassay inhibition method for confirming the specificity of positive hepatitis B surface antigen reactions and for survey of antibodies to the antigen. Vox Sanguinis, 32, 125-130.

Lange, W., and Köhler, H. (1978). Nachweis von Antikörpern gegen HBs-Antigen mit dem modifizierten Microelisa-Hepanostika-Test. Deutsche medizinische Wochenschrift, 103, 1873-1877.

Leonard, J. P., Doyen, G., and Beckers, C. (1974). Simplified and sensitive detection of antibody to Australia antigen using a solid-phase radioimmunoassay. In Radioimmunoassay and Related Procedures in Medicine. Proceedings of a Symposium, vol. 2, pp. 367375. International Atomic Energy Agency, Vienna.

Müller, R., Stephan, B., Kramer, R., and Deicher, H. (1975). Detection of antibody to hepatitis Bs-antigen in patients with acute and chronic hepatitis as measured by a modified procedure of the radioimmunoassay Ausria I ${ }^{125}$. Vox Sanguinis, 29, 330-337.

Pesendorfer, F. X. (1976). Hepatitis-B-SurfaceAntikörper (Nachweis, Häufigkeit, klinische Bedeutung). Wiener klinische Wochenschrift, 88, Supplement, 57, 1-22.

Wolters, G., Kuijpers, L., Kačaki, J., and Schuurs, A. (1976). Solid-phase enzyme-immunoassay for detection of hepatitis B surface antigen. Journal of Clinical Pathology, 29, 873-879.

Wolters, G., Kuijpers, L. P. C., Kačaki, J., and Schuurs, A. H. W. M. (1977). Enzyme-linked immunosorbent assay for hepatitis B surface antigen. Journal of Infectious Diseases, 136, Supplement (October), S311S317.

Requests for reprints to: $\mathrm{Dr}$ G. Wolters, Organon Scientific Development Group, Biochemical Research and Development Laboratories, Oss, The Netherlands. 